\title{
Some methodological questions concerning advection measurements: a case study
}

\author{
B. Heinesch - M. Yernaux - M. Aubinet
}

Received: 21 June 2005/Accepted: 14 June 2006

CSpringer Science+Business Media B.V. 2006

\begin{abstract}
A dataset from two campaigns conducted at the Vielsalm experimental site in Belgium was used as a basis for discussing some methodological problems and providing intermediate results on estimating $\mathrm{CO}_{2}$ advection. The analysis focused on the horizontal $\left[\mathrm{CO}_{2}\right]$ gradient and on the vertical velocity $w$, the variables most affected by uncertainty. The sampling error for half-hourly horizontal $\left[\mathrm{CO}_{2}\right]$ gradients was estimated to be $1.3 \mu \mathrm{mol} \mathrm{mol}^{-1}$. Despite this important random error for half-hour estimations of $\left[\mathrm{CO}_{2}\right]$, the mean horizontal $\left[\mathrm{CO}_{2}\right]$ gradients in advective conditions were shown to be representative at the ecosystem scale and to extend only to the lowest part of a drainage sub-layer, which developed in the trunk space. By contrast, under daytime conditions, this gradient was shown to be more sensitive to local source heterogeneities. The estimation of the short-term averaged vertical velocity $(\bar{w})$ was the greater source of error when computing advection terms. The traditional correction methods used to obtain $\bar{w}$ are discussed and a (co)sine correction is tested to highlight the instrumental origin of the offset in $w$. A comparison of measurements by sonic anemometers placed close together above the canopy showed that the uncertainty on $\bar{w}$ was $0.042 \mathrm{~m} \mathrm{~s}^{-1}$, which is of the same order of magnitude as the velocity itself. In addition, as the drainage sub-layer is limited to the lowest part of the canopy, the representativeness of $\bar{w}$ is questionable. An alternative computation using the divergence of the horizontal wind speed in the trunk space produced a $\bar{w}$ estimation that was four times lower than the single-point measurement. However, this value gives a more realistic estimate of the vertical advection term and improves the $\mathrm{CO}_{2}$ budget closure at the site.
\end{abstract}

Keywords Advection $\cdot \mathrm{CO}_{2}$. Drainage flows · Forest · Night flux · Vertical velocity

B. Heinesch $(\varangle) \cdot$ M. Yernaux $\cdot$ M. Aubinet

Unité de Physique des Biosystèmes, Faculté des Sciences Agronomiques de Gembloux,

8 avenue de la Faculté, B-5030 Gembloux, Belgium

e-mail: heinesch.b@fsagx.ac.be 


\section{Introduction}

The past decade has seen the development of continental measurement networks of $\mathrm{CO}_{2}$, sensible and latent heat fluxes, mainly over forests, and based on the eddy covariance technique. Measurements made using this technique can be considered as representative of the net ecosystem exchange (NEE) only if the turbulence in the atmospheric roughness sub-layer is fully developed. As this hypothesis does not hold up under certain conditions, especially stable atmospheric conditions, the NEE measured during these periods should be treated with caution (Massman and Lee 2002). Under low-level turbulence conditions, extra terms in the expression of the NEE derived from the mass conservation equation of the tracer need to be taken into account, including the storage of the tracer behind the measurement level $(S)$, vertical $\left(F_{\mathrm{V}}\right)$ and horizontal $\left(F_{h}\right)$ advection, and the horizontal divergence of turbulent fluxes. Even when the storage term is taken into account, most sites show an underestimation of the NEE under stable atmospheric conditions (Aubinet et al. 2000; Gu et al. 2005). This highlights the need to study these extra terms. Though in this paper, we restrict the discussion to advective terms only.

Vertical advection can be evaluated by using measurements from a single tower. Because these measurements were already available, several evaluations of the vertical advection of $\mathrm{CO}_{2}$ had already been proposed (Lee 1998; Baldocchi et al. 2000; Paw U et al. 2000). Theoretical arguments show that vertical and horizontal advection are closely linked and therefore the two terms must be evaluated simultaneously in order to give a complete $\mathrm{CO}_{2}$ budget (Finnigan 1999; Lee 1999). Unfortunately, $F_{\mathrm{v}}$ and $F_{\mathrm{h}}$ are characterised by an important variability that results mainly from vertical velocity and horizontal $\mathrm{CO}_{2}$ gradient variabilities. This, as well as conceptual and technical difficulties, means that caution is needed when discussing the closure of the complete budget (i.e. the ability of the measured NEE to represent the true biological flux).

Several groups have now given the complete $\mathrm{CO}_{2}$ budget, with varying success when trying to obtain the closure. Aubinet et al. (2003) found that vertical and horizontal advective terms were of opposite signs and of a similar order of magnitude, but they did not attempt to estimate the source term. Feigenwinter et al. (2004) also found that $F_{v}$ and $F_{h}$ were of opposite signs ( +4 and $-4.5 \mu \mathrm{mol} \mathrm{m}^{2} \mathrm{~s}^{-1}$, respectively) and that they compensate during the night. In addition, they found that horizontal advection was not negligible during the day $\left(+2.4 \mu \mathrm{mol} \mathrm{m}^{2} \mathrm{~s}^{-1}\right)$, which reduced the sink intensity by $20 \%$. Staebler et al. (2004) found that the inclusion of $F_{\mathrm{V}}$ and $F_{\mathrm{h}}(+0$ and $+1.7 \mu \mathrm{mol} \mathrm{m} \mathrm{s}^{-1}$, respectively) in the balance allows the NEE on stable nights to increase towards a value close to that observed during turbulent nights $(+4.4$ compared to $\left.+4.7 \mu \mathrm{mol} \mathrm{m}^{2} \mathrm{~s}^{-1}\right)$. However, this was observed only in summer. During other seasons, advective terms did not compensate for the underestimation of fluxes under stable conditions. Marcolla et al. (2005) found that $F_{\mathrm{v}}$ and $F_{\mathrm{h}}$ were of the same sign under stable nighttime conditions $\left(+3\right.$ and $+1.5 \mu \mathrm{mol} \mathrm{m}^{2} \mathrm{~s}^{-1}$, respectively), and their inclusion in the balance therefore led to an increase in nighttime NEE. This site had considerable vegetation cover heterogeneities and therefore showed important discrepancies between the different volumes chosen to compute the advective terms. Finally, a comparison between sites, involving six CARBOEUROPE INTEGRATED PROJECT stations, has been proposed (Aubinet et al. 2005), highlighting the effect of topography and weather conditions on the balance between storage and advection.

In this study, we address some important methodological questions about evaluating advection terms using a dataset obtained at the Vielsalm site from two campaigns 
focusing on advection. We show that the main sources of uncertainty in determining the advection terms are the estimations of vertical velocity and horizontal $\left[\mathrm{CO}_{2}\right]$ gradient. Therefore, we focus on the analysis of these two variables. A sampling strategy for estimating $\mathrm{CO}_{2}$ concentrations is described and we analyse the spatial and temporal representativeness of $\mathrm{CO}_{2}$ concentration measurements as well as the spatial representativeness of the vertical velocity evaluations. The study relies on a previous analysis of wind flow at Vielsalm by Aubinet et al. (2003, referred hereafter as A03) who also gave an initial evaluation of the advective terms.

\section{State of the art}

\subsection{Conservation equation}

The carbon dioxide mass conservation equation states that the $\mathrm{CO}_{2}$ produced or absorbed by the biological source/sink is either stored in the air or removed by flux divergence in all directions. This equation has been developed and discussed in detail, notably by Finnigan (1999), Finnigan et al. (2003) and Feigenwinter et al. (2004). After applying Reynolds decomposition, spatial integration over a control volume of height $h$ and lateral extent $2 L$, ignoring the horizontal turbulent flux divergence and the horizontal variation of the vertical turbulent flux and applying the continuity equation, the equation is reduced to:

$$
\begin{aligned}
\mathrm{NEE}= & \int_{0}^{h} \frac{1}{V_{\mathrm{m}}}\left[\frac{\partial \bar{c}}{\partial t}\right] \mathrm{d} z+\frac{1}{V_{\mathrm{m}}}\left(\overline{w^{\prime} c^{\prime}}\right)_{h}+\int_{0}^{h} \frac{1}{V_{\mathrm{m}}} \bar{w}(z) \frac{\partial \bar{c}}{\partial z} \mathrm{~d} z \\
& +\frac{1}{4 L^{2}} \int_{-L}^{+L} \int_{-L}^{+L} \int_{0}^{h} \frac{1}{V_{\mathrm{m}}}\left(\bar{u} \frac{\partial \bar{c}}{\partial x}+\bar{v} \frac{\partial \bar{c}}{\partial y}\right) \mathrm{d} x \mathrm{~d} y \mathrm{~d} z,
\end{aligned}
$$

where NEE represents the biological source/sink strength term, $c$ is the $\mathrm{CO}_{2}$ mixing ratio, $V_{\mathrm{m}}$ is the molar volume of dry air, $u, v$ and $w$ represent the velocity components in the horizontal $(x, y)$ and vertical $(z)$ directions, respectively. Overbars represent time averages (used here for short-term time averages, typically $30 \mathrm{~min}$ ) and prime departures from instantaneous values. The four terms on the right-hand side represent, respectively, the storage of $\mathrm{CO}_{2}$ in the air of the control volume, the vertical turbulent transport, the vertical advection and the horizontal advection. Lateral integration has already been performed on the first three terms on the righthand side by assuming that they do not vary in the $x$ and $y$ directions. The upper boundary of the box is in the air at the height of the eddy covariance measurement system $(h)$. The vertical advection term may be rewritten (Lee 1998):

$$
F_{v}=\frac{1}{V_{\mathrm{m}}} \bar{w}_{h}\left(\bar{c}_{h}-\langle c\rangle\right)
$$

where

$$
\langle c\rangle=\frac{1}{h} \int_{0}^{h} \bar{c}(z) \mathrm{d} z .
$$


If, for the sake of simplicity, lateral homogeneity is assumed, as is the case at the Vielsalm site as we will show below, the volume may be restricted to a two-dimensional box along the $x$ and $z$ axes and the horizontal advection term may be written:

$$
F_{h}=\frac{1}{2 L} \int_{-L}^{L} \int_{0}^{h} \frac{1}{V_{\mathrm{m}}} u \frac{\partial \bar{c}}{\partial x} \mathrm{~d} x \mathrm{~d} z=\frac{1}{V_{\mathrm{m}}} \int_{0}^{h} u_{x=0}(z) \frac{\partial \bar{c}(z)}{\partial x} \mathrm{~d} z
$$

where the horizontal integration is performed by assuming a horizontally homogeneous horizontal gradient $\left(\left(\partial^{2} \bar{c} / \partial^{2} x\right)=0\right)$ and divergence of horizontal velocity $\left(\left(\partial^{2} \bar{u} / \partial^{2} x\right)=0\right)$. The $x$ axis is oriented downslope and thus a positive (negative) horizontal $\left[\mathrm{CO}_{2}\right]$ gradient reflects an enrichment (depletion) of the air in $\left[\mathrm{CO}_{2}\right]$ when flowing downslope.

The main sources of uncertainty in determining the advection terms concern the estimations of the vertical velocity and the horizontal $\left[\mathrm{CO}_{2}\right]$ gradient, although the horizontal velocity can also be affected by uncertainties. In the canopy, this value can approach the precision of the anemometers and its direction can be variable in conditions of low winds. However, in conditions of well-developed and continuous drainage flows and with relatively sparse undercover vegetation, these problems are reduced. The values of the vertical $\left[\mathrm{CO}_{2}\right]$ gradient are well above the precision of the analyser, and the impact of sampling will be addressed below. We therefore focus on the vertical velocity and the horizontal $\left[\mathrm{CO}_{2}\right]$ gradient.

\subsection{Vertical velocity}

The vertical wind component $\bar{w}$ is obtained from the wind components in the Cartesian coordinate system of the three-dimensional sonic anemometer. In order to represent the motion of the air perpendicular to the long-term streamlines, this value must be corrected for several effects.

(a) A static offset (i.e., a non-zero $\bar{w}$ in the absence of wind) may appear due to electronic problems (Grelle and Lindroth 1994; Lee 1998; Wilczack et al. 2001). This offset probably differs from one sonic type to another and could be tested by placing the sonic in a windless anechoid chamber (Staebler 2003; Lee et al. 2004)

(b) A dynamic offset could also appear, due to flow perturbation induced by the struts of the anemometer and the sensors themselves or by sensor head misalignment relative to the sonic vertical axis. It depends, of course, on the wind direction related to the geometry of the anemometer and the angle of attack of the incoming wind. This source of error for wind components is also known as the (co)sine error because it produces both sine errors in the vertical wind component and cosine errors in the horizontal wind components (Gash and Dolman 2003). Several teams have conducted wind-tunnel calibration trials and shown that the manufacturer's calibration is not always adequate for solving this problem (Grelle and Lindroth 1994; Van der Molen et al. 2004; Heinemann et al. 1997; Shimizu et al. 1999). In particular, Wieser et al. (2001) tested a Gill R2 and reported induced tilt angles for a horizontal incoming wind of $-1.8^{\circ}$ to $+1.4^{\circ}$, depending on wind direction, and deviations from expected tilts of $-1.3^{\circ}$ to $+0.9^{\circ}$, depending on angle of attack (restricted to between $-8^{\circ}$ and $+8^{\circ}$ ). In addition, 
even a proper laminar wind-tunnel calibration may not be valid under turbulent conditions because of the high sensitivity of the wakes to the nature of the approaching flow (Högström and Smedman 2004). The problems (a) and (b) are of a purely technical origin. Below, apart from a mention to the contrary, we will use the term 'technical offset' to characterise both the static and the dynamic offsets.

(c) Apart from anemometers that are perfectly perpendicular to a regular surface, we can expect a tilt of the anemometer towards the long-term mean streamlines. In simple topography, these long-term streamlines are supposed to be parallel to the soil or to the canopy surface and the anemometer is generally placed along the vertical axis, producing a tilt for sloping sites.

Coordinate rotation can be used to address these problems, with several approaches. The method recommended previously was a two-axis rotation aligning the axis $x$ parallel to the mean wind velocity and applied after each averaging period: the first rotation forced $\bar{v}$ to 0 and the second rotation, with an angle $\beta^{\prime}$, forced $\bar{w}$ to 0 (Kaimal and Finnigan 1994; Aubinet et al. 2000). This method therefore supposed that the mean vertical velocity $\bar{w}$ was zero for each averaging period. Lee (1998) was the first to point out that this hypothesis was not necessarily true and that real non-zero vertical velocity could be observed under certain conditions.

An alternative rotation procedure was then proposed, and was extensively described by Wilczack et al. (2001). It differs from the preceding method with regard to the second rotation, which is based on the assumption that there is no mean vertical component over a long period (long compared to the short-term averaging period of $30 \mathrm{~min}$ ). In these conditions, non-zero values of $\bar{w}$ can be due either to the causes (a) to (c) cited above or to movements induced by some specific climatic forcing. It is hypothesised that the second would decay over the long term due to its random behaviour whereas the first would remain as it is systematic. It could then be removed by a correction based on regression on the wind components or on the rotation angles. Different ways to define this long-term coordinate system (regression on wind velocity components or on rotation angles) have been proposed and compared (Paw U et al. 2001; Baldocchi et al. 2000). However, the differences between them are minor. We used the method 1 mentioned in Paw U et al. (2001) whereby the second rotation is applied with a fixed angle $\beta$ rather than with a variable angle $\beta^{\prime} . \beta$ is supposed to be dependent on wind direction and is obtained by imposing a sinusoidal regression on the relation between $\beta^{\prime}$ and azimuthal angle. In the present study, we refer to this method as the planar fit method (PFM), although, strictly speaking, this appellation refers to the regression on wind velocities. In the case of more complex topography or in the presence of a specific flow perturbation due to tower influence or to obstacles in the sonic anemometer surroundings, the sinusoidal regression may be inadequate. The PFM can therefore be adapted and another regression can be used. In that case, the fixed second rotation angle $\beta$ is simply taken as the mean $\beta^{\prime}$ for each sector of wind direction. This method is therefore more versatile and probably more suited to non-homogeneous terrains. Here, we refer to this method as the non-planar fit method (NPFM). After applying the NPFM, $\bar{w}$ represents the short-term mean wind component that is perpendicular to the long-term mean streamlines.

On the other hand, Van der Molen et al. (2004) proposed applying a calibration to the raw data to correct for flow perturbation induced by the anemometer struts and the sensors themselves. This correction was presented as generic for a given 
geometry of sonic anemometer and superimposed on the manufacturer's calibration. The correctly calibrated vertical wind speed $w_{\mathrm{c}}$ was calculated from

$$
w_{\mathrm{c}}=w \frac{\sin \alpha}{\sin \alpha+\varepsilon_{\sin }}
$$

where $\alpha$ indicates the angle of attack in degrees, and $\varepsilon_{\text {sin }}$ can be described as a third-order polynomial with parameters obtained using a wind-tunnel experiment. As the angle of attack is determined from the measured wind components that are themselves subject to (co)sine errors, it must be derived in an iterative manner. This approach is different, of course, because it corrects only the technical offset and does not take tilt correction into account. However, the comparison of NPFM and (co)sine corrected data allows the importance of the technical offset in the whole correction to be assessed.

Another possibility for computing $\bar{w}$ could be to use the continuity equation. From incompressible mass continuity and in a two-dimensional (2D) pattern, $\bar{w}$ is given by:

$$
\bar{w}(h)=-\int_{0}^{h} \frac{\partial \bar{u}}{\partial x} \mathrm{~d} z,
$$

so that Eq. (5) allows for an evaluation of $\bar{w}$ at a height $h$ from the divergence of $\bar{u}$ along the slope. This approach will be discussed below.

\section{$2.3 \mathrm{CO}_{2}$ concentration}

Horizontal gradients are deduced from the difference between concentration measurements made at different locations using infrared gas analysers (IRGA). As these differences are often low, they are subject to considerable uncertainty. In order to suppress the main causes of instrumental uncertainty, it is recommended that the same analyser be used for all measurements, which implies long (several tens of metres) sampling tubes. Since important pressure differences can arise along the tubes, it is therefore important to devise a tubing system that will maintain the same pressure inside the IRGA. Such can be achieved by using tubes of similar length for all sampling points or by using a two-pump system.

In addition to the instrumental errors, uncertainty might arise from sample tube positioning. Under stable conditions and in the first 1-m layer close to the soil, the mean vertical $\mathrm{CO}_{2}$ gradient is about $20 \mu \mathrm{mol} \mathrm{mol}^{-1} \mathrm{~m}^{-1}$. Therefore, an error of only $0.05 \mathrm{~m}$ in the height of a sampling point can induce a systematic error of $1 \mu \mathrm{mol} \mathrm{mol}^{-1}$ in the horizontal $\left[\mathrm{CO}_{2}\right]$ differences. To define a sampling height is not straightforward. First, on irregular terrain, the level of the soil surface is not always clearly defined. Second, the aim is to measure the evolution of the $\mathrm{CO}_{2}$ concentration along a streamline but, due to obstacles, the streamlines are not always parallel to the soil surface. Finally, interpretating the results is difficult because horizontal gradients, especially those measured near the soil surface, can always be influenced by local source heterogeneity. The measurements of a sampling point can be strongly affected by its immediate surroundings (dead wood, etc.). In this case, the measured horizontal gradients would not be representative at the ecosystem scale. This problem is closely linked to the extent of the footprint zone of the sampling points, and the footprint extent, even if difficult to estimate, is larger at night than during the day. This 
means that stable nighttime measurements will be more representative of ecosystem behaviour than daytime measurements.

\section{Material and methods}

\subsection{Site description}

The study site is in Vielsalm in the Belgian Ardennes $\left(50^{\circ} 18^{\prime} \mathrm{N}, 6^{\circ} 00^{\prime} \mathrm{E}\right.$, altitude $450 \mathrm{~m}$ ), on the side of an open valley, with a uniform slope north-west oriented and of the order of $3 \%$. The climate is temperate maritime. The stand is mixed, comprising Douglas fir (Pseudotsuga menziesii [Mirb.] Franco), beeches (Fagus sylvatica L.), silver fir (Abies alba Miller), Norway spruce (Picea abies [L.] Karst.), Scots pine (Pinus sylvestris L.) and pedonculate oak (Quercus robur L.). The tower is at the interface of two sub-plots, one sub-plot dominated by Douglas fir, $36 \mathrm{~m}$ tall with very sparse undercover, and the other sub-plot dominated by beech, $27 \mathrm{~m}$ tall with no undercover. The distance to the forest edge is $1,500 \mathrm{~m}$ in a south-west direction and $500 \mathrm{~m}$ in a north-east direction; these are the dominant wind directions. A clearing with a 5-ha tree nursery is $250 \mathrm{~m}$ from the tower in the upslope direction (Fig. 1b). The leaf area index of the canopy is 5.0. A more complete description of the site can be found in Laitat et al. (1999); the site was a part of the successive Euroflux, CarboEuroflux and CarboEurope networks.

\subsection{Measurements}

A detailed description of the long-term flux measurement system, including eddy covariance system and a micrometeorological station, was given by Aubinet et al. (2001). In addition to this set-up, a system devised to estimate the advection terms was installed for four months in summer 2002 in the beech sub-plot and for one month in spring 2003 in the Douglas fir sub-plot. It measured the $\mathrm{CO}_{2}$ concentration of the air and the horizontal velocity at several points below the eddy covariance sensor. In addition, two three-dimensional sonic anemometers (Gill R2 and Gill R3, Gill Instruments, Lymington, UK) were used to estimate the vertical component of the velocity, and were placed at the top of the main tower, at a height of 40-m, fixed on vertical booms $4 \mathrm{~m}$ long at two opposite corners of the tower and separated horizontally by $2 \mathrm{~m}$. They were both used in the calibrated mode.

Half-hourly averages of the air $\mathrm{CO}_{2}$ concentrations were measured at 20 points (Fig. 1a). A03 showed that, in stable conditions, a drainage flow developed and was maintained continuously along the slope, prompting us to limit the set-up to a $2 \mathrm{D}$ framework. Verifications of the validity of this hypothesis were made and confirmed later. Three vertical profiles were taken, two of them on two secondary masts situated $89 \mathrm{~m}$ from each other along the slope direction, with four points $(0.5,1,3$ and $6 \mathrm{~m})$, and the third one at the main tower, not aligned with the two secondary masts, with eight sampling points $(0.5,1,3,6,16,24,32$ and $36 \mathrm{~m})$. In addition, one horizontal profile with four sampling points, each of them at a height of 1-m, was taken between the two secondary masts. These points were evenly distributed along the transect.

The tubes for air sampling were polyurethane ( $4 \mathrm{~mm}$ inner diameter, FESTO, Esslingen, Germany) and meshed at the inlet. The choice of tube material can have an important effect on the flushing time, so laboratory tests were conducted by injecting a 

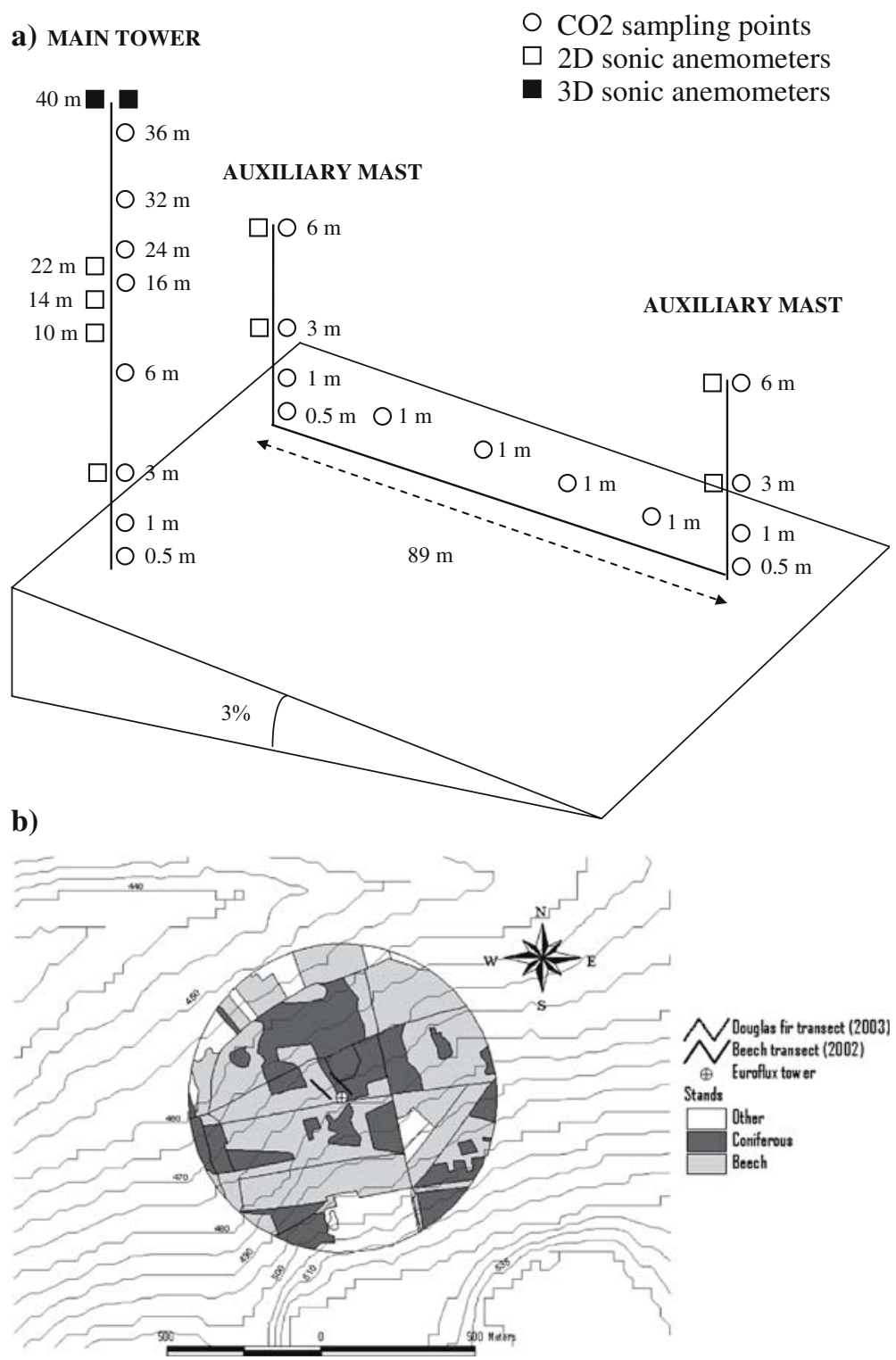

Fig. 1 (a) Schematic of experimental set-up. (b) Map of topography and land use distribution around the flux tower; position of the two hosizontal transects and the main tower

reference gas $\left(350 \mu \mathrm{mol} \mathrm{mol}^{-1}\right.$ of $\left.\mathrm{CO}_{2}\right)$ in a tube previously flushed with ambient air and observing the evolution of $\left[\mathrm{CO}_{2}\right]$ towards the reference level. With tube length, flow rate and flushing time representative of field conditions, $\mathrm{CO}_{2}$ concentration reached within $0.2 \mu \mathrm{mol} \mathrm{mol}^{-1}$ of the reference level.

In order to avoid relying too much on the pressure correction of the IRGA, pressure differences in the IRGA chamber were avoided by using a system with two pumps. The first pump (KNF N86KN18, $151 \mathrm{~min}^{-1}$, Village Neuf, France) transported the air at a fast flow rate from the sampling points to a common tube near the IRGA. This 
main flow was then sub-sampled by a second and less powerful pump at a slower flow rate from the common tube to the IRGA. The lines were sampled one by one but air was flushed constantly along all the lines (with two more pumps, KNF N86KN18) in order to reduce the total cycling time ( $3 \mathrm{~min} 40-\mathrm{s}$ ). The response time of the system (i.e., the time needed to purge the flow path downstream from the valve selecting the sampling line of air coming from a previous sampling point) was evaluated to be shorter than $3 \mathrm{~s}$. Therefore, after line switching, a delay time of $4 \mathrm{~s}$ was imposed before recording data. After this delay time, five consecutive samples were taken at a frequency of $0.7 \mathrm{~Hz}$. Finally, each measurement corresponded to an average of eight periods with five samples each, taken at uniform frequency over the half-hour period. All concentrations were measured using the same infrared gas analyser (model LI6262 with pressure transducer, LI-COR Inc., Lincoln, NE, USA) which was calibrated weekly. Air at high $\mathrm{CO}_{2}$ concentration was flushed onto the connectors in order to detect possible leakages and on each line end in order to estimate flushing times and therefore possible restrictions of the tube along the line.

Horizontal velocity was measured at four heights $(3,10,14$ and $22 \mathrm{~m})$ on the main tower using home-made sonic anemometers. These $2 \mathrm{D}$ anemometers provided a path length of $0.30 \mathrm{~m}$, a working frequency of $3 \mathrm{~Hz}$ and a proper dimension to avoid significant distortion of the flow field. More detail about this device can be found in Wang et al. (1999). The anemometers were calibrated by comparison with the Gill R2 anemometer and they performed well for low mean wind velocities. During the 2003 campaign, two similar anemometers were added to each secondary mast (at heights of 3 and $6 \mathrm{~m}$, Fig. 1a) in order to estimate the divergence of the horizontal velocity.

Vertical velocity was computed in two ways. The first method was based on the assumption that vertical velocity should be zero on average in every wind sector. The correction consisted of applying a second rotation angle $\beta$ defined in each sector as the average angle observed in this sector (NPFM). The NPFM was established using measurements taken only in conditions of winds higher than $2 \mathrm{~m} \mathrm{~s}^{-1}$ as suggested by Finnigan (1999). Additionally, the (co)sine correction using the coefficients given by Van der Molen et al. (2004) for the Gill R2 and R3 was also applied in order to analyse the characteristics of the applied correction more deeply. The second method was based on the continuity equation and consisted of deducing $\bar{w}$ from the vertical profiles of horizontal velocity using Eq. (5).

\section{Results and discussion}

\subsection{Characteristics of the drainage sub-layer}

In A03 it was shown that, under stable conditions $\left(\left(z-z_{d}\right) / L>1\right)$ at the tower top, where $z_{d}$ is the zero plane displacement height and $L$ is the Obukhov length), the air below the canopy flowed continuously downslope and was completely decoupled from the flow above the canopy. This suggested the presence of drainage flows that develop in a shallow sub-layer confined to the trunk space, which we refer to as the 'drainage sub-layer'. It was not possible to estimate the drainage sub-layer depth in A03 because the uppermost in-trunk space anemometer was placed too low and therefore was still within the drainage sub-layer. We improved the set-up by taking a new profile at $3,10,14$ to $22 \mathrm{~m}$. The resultant horizontal wind vectors were computed at each height for eight classes of the 40-m high wind direction (Fig. 2). Up to $14 \mathrm{~m}$, the 
Fig. 2 Resultant wind vectors (speed in $\mathrm{m} \mathrm{s}^{-1}$ ) computed for eight direction classes of the $40-\mathrm{m}$ high wind direction $\left(337.5^{\circ}-22.5^{\circ}, 22.5^{\circ}-67.5^{\circ}\right.$, $67.5^{\circ}-112.5^{\circ}, 112.5^{\circ}-157.5^{\circ}$, $157.5^{\circ}-202.5^{\circ}, 202.5^{\circ}-247.5^{\circ}$, $247.5^{\circ}-292.5^{\circ}, 292.5^{\circ}-337.5^{\circ}$ ).

$0^{\circ}$ corresponds to north. Established under stable atmospheric conditions $\left(\left(z-z_{d}\right) / L>1\right)$ for $3 \mathrm{~m}$ (filled squares), $10 \mathrm{~m}$ (filled triangles), $14 \mathrm{~m}$ (open diamonds) and $22 \mathrm{~m}$ (open circles)
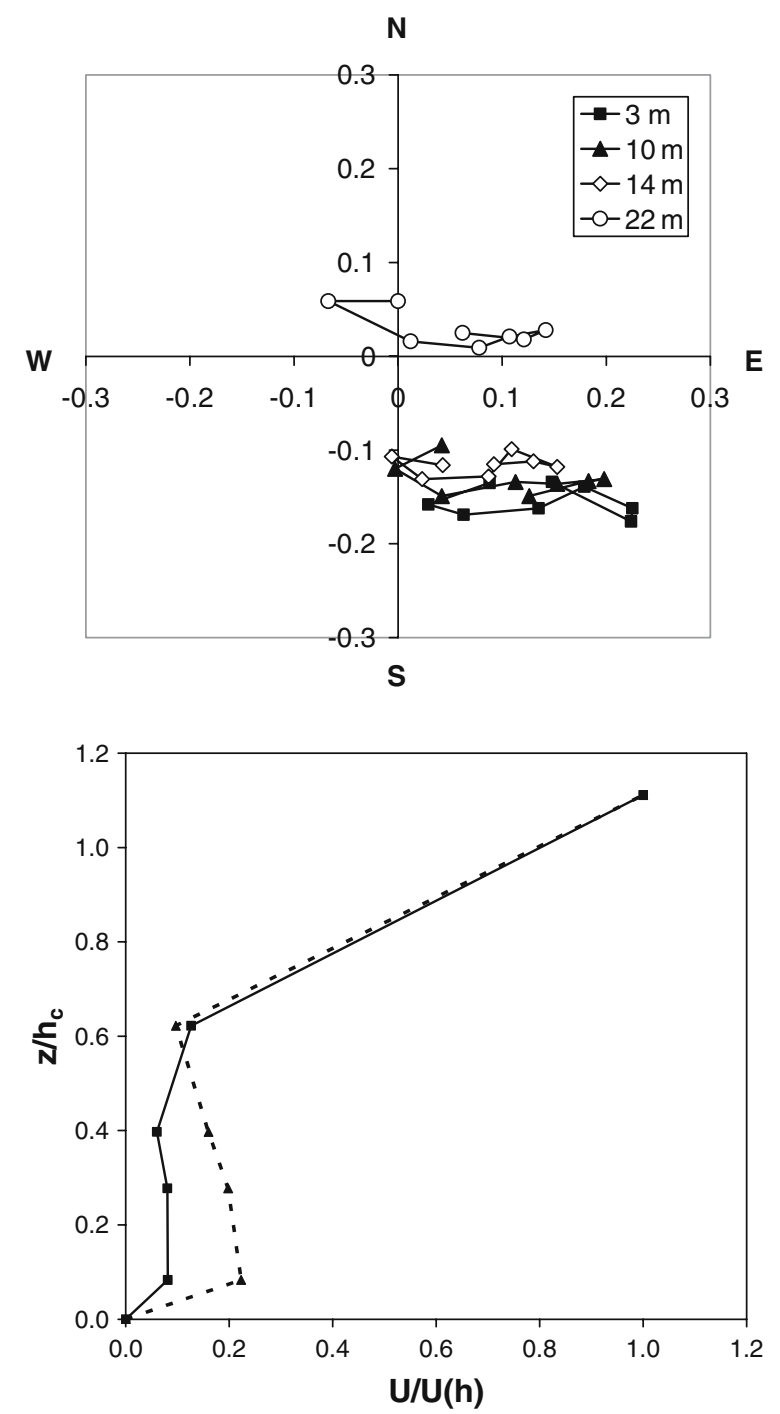

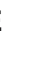

Fig. 3 Vertical profile of horizontal wind velocity for neutral conditions (solid line) and stable conditions (dotted line). Normalized by the wind above the canopy (canopy height $h_{c}$ fixed to $36 \mathrm{~m}$ ) 
arising from above the canopy and thus prevents the destruction of the drainage sublayer below. In addition, the radiative cooling in the crown space probably produces downward sinking air that feeds the cold air drainage.

\section{$4.2\left[\mathrm{CO}_{2}\right]$ measurements}

Storage and vertical and horizontal advection estimates are based notably on $\left[\mathrm{CO}_{2}\right]$ differences. In addition to the experimental uncertainty, these concentrations are subject to considerable spatial and temporal variability. Here, we attempt to estimate the impact of this variability on the fluxes.

In order to evaluate the uncertainty caused by temporal variability, high frequency measurements of $\left[\mathrm{CO}_{2}\right]$ were performed continuously over one week on the same inlet point placed at a height of 1-m. The evolution of the signal over a half-hour period under advective conditions is given in Fig. 4. It appears that strong negative peaks about $1 \mathrm{~min}$ long were superimposed on the general evolution of the concentrations, possibly associated with bursts of air arising from above the canopy, although no clear correlation with vertical velocities above the canopy was found. Anyway, the consequence is that the presence of these peaks might induce significant uncertainty in estimating the half-hourly averaged $\left[\mathrm{CO}_{2}\right]$ and therefore in our estimation of storage and advection. In order to estimate the sampling error resulting from these short-term fluctuations, we compared the average signal with a signal artificially sampled with different frequencies.

To do this, the signal was sampled at a given frequency $n$, and the operation was repeated several times, using a random point of departure each time. Each realization produced a mean $\left[\mathrm{CO}_{2}\right]$ for the half-hour period. The standard deviation of these mean concentrations is a measure of the uncertainty due to sampling over this halfhour period. The number of realizations was thought to be high enough to obtain a constant standard deviation for a given half-hour period (20 in our case).

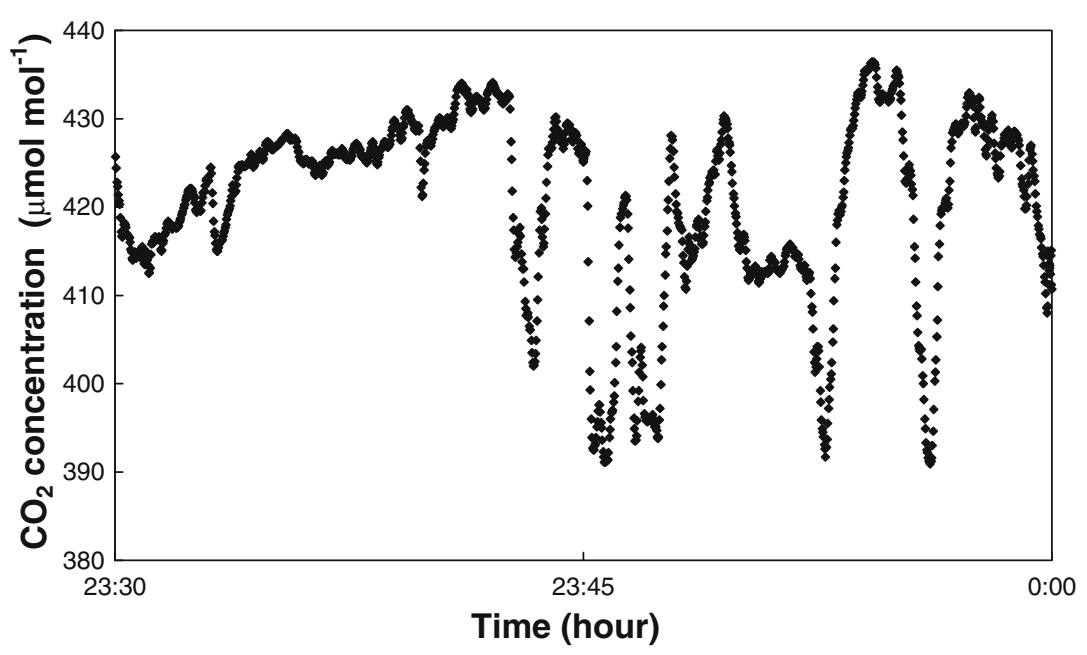

Fig. 4 Evolution over time of the $1-\mathrm{m} \mathrm{CO}_{2}$ concentration over one stable half-hour period $\left(u_{*}=\right.$ $0.03 \mathrm{~m} \mathrm{~s}^{-1}$ ). 


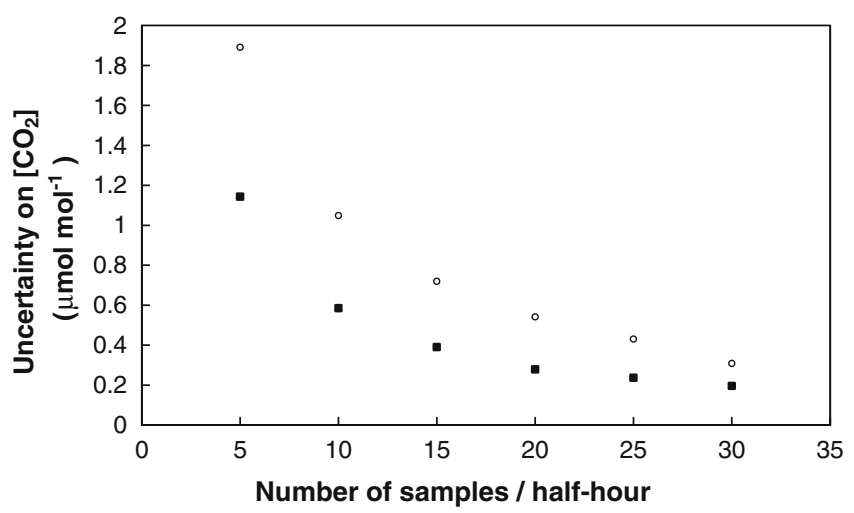

Fig. 5 Uncertainty of $\mathrm{CO}_{2}$ concentrations due to sampling under unstable/weakly stable conditions (solid squares; 64 half-hours) and under stable conditions (open circles; 80 half-hours)

The evolution with the number of samples of the average $\left[\mathrm{CO}_{2}\right]$ uncertainty is given in Fig. 5, separately for unstable/weakly stable and stable atmospheric conditions. The uncertainty is larger, of course, under stable atmospheric conditions because the continuous signal is more variable. The storage and advection computations are based on the difference between two $\left[\mathrm{CO}_{2}\right]$ measured successively at the same point or simultaneously at two locations. Here we are therefore concerned mainly with the uncertainty about the difference of $\left[\mathrm{CO}_{2}\right]$ given by the value in Fig. 5 multiplied by $\sqrt{2}$ as a result of the propagation of random errors in a difference $\left(\varepsilon_{\Delta\left[\mathrm{CO}_{2}\right]}=\sqrt{\varepsilon_{\left[\mathrm{CO}_{2}\right]}^{2}+\varepsilon_{\left[\mathrm{CO}_{2}\right]}^{2}}\right)$ (Taylor 1997). This suggests that the uncertainty due to sampling under stable conditions is about $1.9 \mu \mathrm{mol} \mathrm{mol}^{-1}$ when measurements were taken five times per half hour and fell to below $0.6 \mu \mathrm{mol} \mathrm{mol}^{-1}$ when there were more than 20 measurements per half hour. In our case, where there were eight measurements per half hour, the uncertainty was about $1.3 \mu \mathrm{mol} \mathrm{mol}^{-1}$. The impact of this error on the different fluxes depends on the values of the $\left[\mathrm{CO}_{2}\right]$ difference themselves and therefore differs for each flux. For the storage, if we assume a similar uncertainty at all heights, an upper limit of the flux uncertainty due to sampling is about $0.42 \mu \mathrm{mol} \mathrm{m}^{-2} \mathrm{~s}^{-1}$, and represents a significant fraction $(10 \%$ or more) of the flux. In practice, the error would be lower because the temporal variability (i.e., the negative peak heights) of the concentration is expected to be lower at greater heights. The impact of sampling uncertainty on vertical advection is expected to be smaller. Indeed, vertical concentration gradients are much larger and the relative uncertainty regarding the $\left[\mathrm{CO}_{2}\right]$ difference is relatively less important: typically, it would be lower than $2 \%$. The impact on horizontal advection is the most important one. If the estimate is based on only two point measurements, the percentage error could be between $20 \%$ and $40 \%$. However, the uncertainty could be reduced by using a transect of several points. In these conditions, a compromise should be obtained between the number of points and the sampling frequency on each point. These significant uncertainties result in a very 'noisy' signal for horizontal gradients and highlight the need for long-term field campaigns.

The horizontal $\left[\mathrm{CO}_{2}\right]$ gradients are presented in Figs. 6 and 7. In Fig. 6, horizontal $\left[\mathrm{CO}_{2}\right]$ profiles taken under stable conditions are presented, while in Fig. 7 vertical profiles of the horizontal $\left[\mathrm{CO}_{2}\right]$ gradients between the higher and lower transect points are shown under stable (Fig. 7a) and daytime (Fig. 7b) conditions. Two profiles 


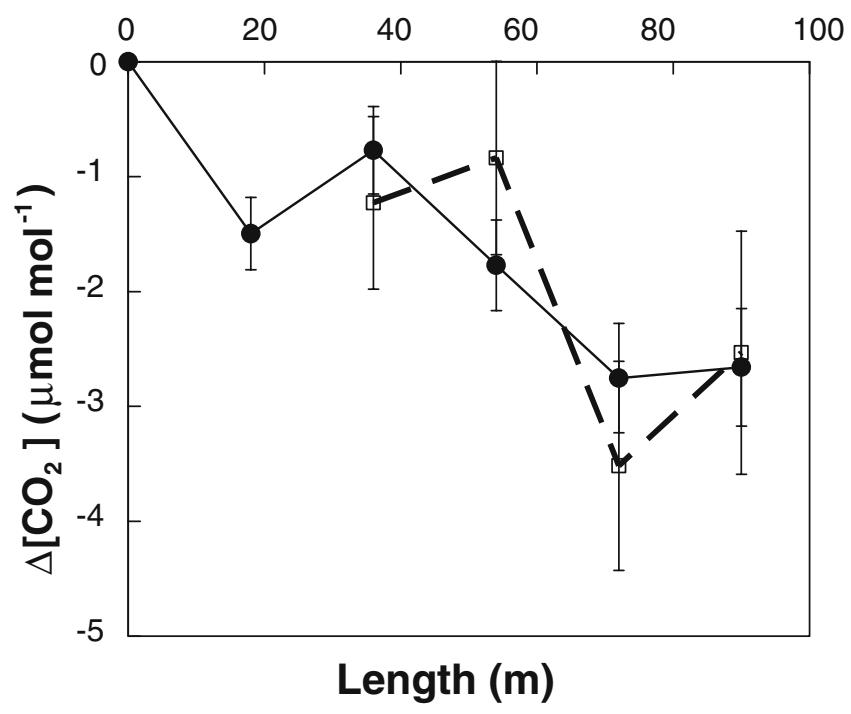

Fig. 6 Horizontal profiles of $\left[\mathrm{CO}_{2}\right]$ measured along the slope direction under stable conditions $\left(\left(z-z_{d}\right) / L>0.3\right)$ at a height of 1-m. Solid line: beech campaign, dashed line: Douglas fir campaign. Each point is an average on 600 (250) measurements in the beech (Douglas fir). The $20 \mathrm{~m}$ point for the Douglas fir campaign was discarded due to bad vertical positioning. The error bars represent the standard error of the mean

are presented in each figure, each one corresponding to one campaign. These two campaigns were conducted in two successive years (over 120 days in 2002, and over 26 days in 2003) and in both cases, the transects were oriented along the slope but they were taken at two locations placed laterally $50 \mathrm{~m}$ from each other, one in the beech sub-plot and the other in the Douglas fir sub-plot.

These results confirm the existence of a negative and repeatable $\left[\mathrm{CO}_{2}\right]$ gradient under stable conditions, a result already obtained by A03 on the basis of two single measurements. However, the representativeness of the result was questionable since it could be due to a very local source distribution. The fact that the gradient presents a fairly regular shape along the transect and was similar during the two campaigns confirms that the measurements are repeatable both longitudinally and transversally and are therefore representative at the ecosystem scale. In addition, as the two transects were taken in two successive years and agree with the A03 results, this suggests that the observed gradient is not subject to high interannual variability. This would confirm that, because of its particular topography and land cover, the Vielsalm site is suitable for repeatable horizontal advection measurements. This is apparently not so for all sites. Marcolla et al. (2005) found a locally variable horizontal gradient, being positive in the first half of the profile and negative in the second half, probably due to changes in source repartition. Also, Staebler and Fitzjarrald (2004) found large interannual differences in their $\left[\mathrm{CO}_{2}\right]$ patterns and suggested that they were due to an interannual change in source locations due to the impact of localised drought at the site.

Figures 6 and 7 a show that the average value of $\left[\mathrm{CO}_{2}\right]$ gradients under stable conditions is about $-0.03 \mu \mathrm{mol} \mathrm{mol}{ }^{-1} \mathrm{~m}^{-1}$ at a height of $1-\mathrm{m}$ and decreases steadily with height to decay at a height between 4 and $6 \mathrm{~m}$. This suggests that horizontal advection does not affect the whole drainage sub-layer but is limited to its lower part. 
Fig. 7 Vertical profile of horizontal $\left[\mathrm{CO}_{2}\right]$ gradient under stable conditions (a, $\left.\left(z-z_{d}\right) / L>0.3\right)$ and daytime conditions (b, 10:00 UCT to 16:00 UCT) for the beech campaign (solid line) and the Douglas campaign (dashed line). The error bars represent the standard error of the mean
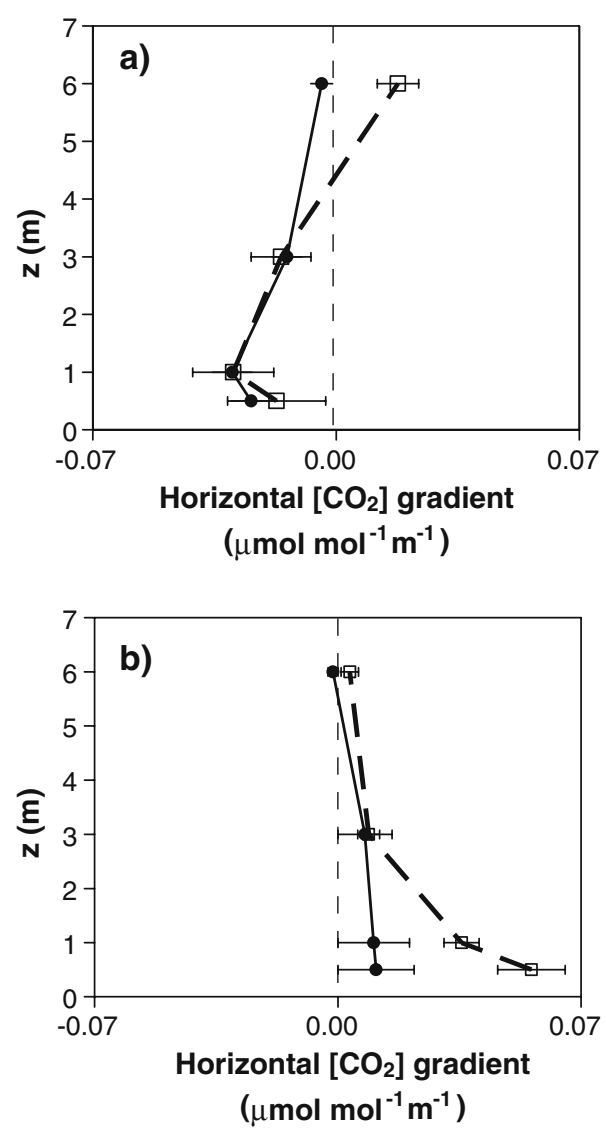

The hypothesis of a zero horizontal gradient of $\left[\mathrm{CO}_{2}\right]$ above the drainage sub-layer is supported by recent modelling of the drainage flows. Indeed, Yi et al. (2005) showed that a very stable layer developed just above the drainage sub-layer and prevented vertical dispersion of scalars out of the drainage sub-layer.

Vertical profiles of horizontal $\left[\mathrm{CO}_{2}\right]$ gradients under unstable conditions are presented in Fig. $7 b$. The gradient is clearly positive, a horizontal gradient of about $0.01-$ $0.06 \mu \mathrm{mol} \mathrm{mol}-1 \mathrm{~m}^{-1}$ being observed in the $4 \mathrm{~m}$ deep layer above the soil. However, this does not necessarily imply an advection flow because the gradient is not aligned with the wind in the trunk space. Obviously, the $\left[\mathrm{CO}_{2}\right]$ field at $1-\mathrm{m}$ is not uniform, despite the turbulent conditions and probably due to strong source heterogeneity in the footprint of the measurements under unstable conditions.

\subsection{Vertical velocity}

In order to evaluate the impact of the uncertainty on vertical velocity $\bar{w}$ due to the rotations, we compared the results from two anemometers (one Gill R2 and one Gill R3) placed at the same height at the top of the Vielsalm tower and spaced $2 \mathrm{~m}$ apart laterally, over a period of four months. Figure 8 shows the relationship between the tilt angle and the azimuthal angle for both instruments. The main features of this relationship are: 
Fig. 8 Relationship between tilt angle and azimuthal angle for (a) Gill R2 at the top of the tower (40-m) and (b) Gill R3 at the top of the tower (40-m). Squares: not calibrated for (co)sine error. Triangles: calibrated for (co)sine error. Established over a period of four months (2,520 data per anemometer). Error bars are standard error of the mean
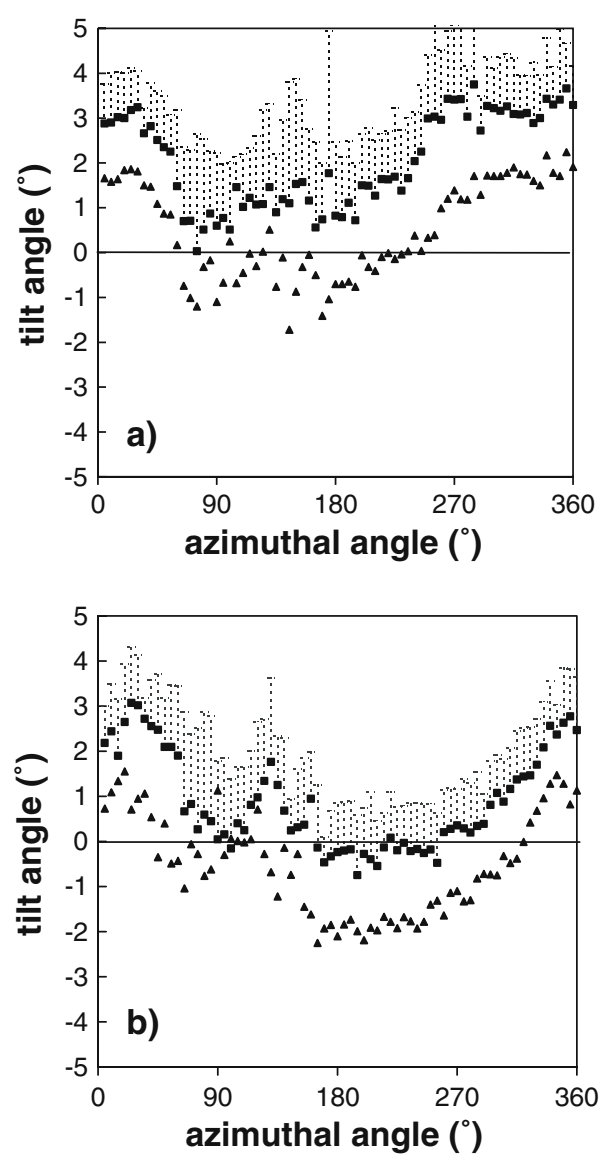

- A sinusoidal shape that reflects the inclination of the two anemometers compared to the mean streamlines. The amplitude of the sinusoid was $1.3^{\circ}$ in both cases, but the phases were different, suggesting that the sonics were inclined in different directions relative to the streamlines. As these sonics were placed at the top of 4-m long vertical booms, it was difficult to control their verticality, explaining that the amplitude and phase did not fit the slope.

- Systematic offsets of $2^{\circ}$ and $0.9^{\circ}$, respectively

- Some disturbances around $120^{\circ}$. These disturbances may be attributed to canopy surface irregularities (presence of a high tree close to the tower, differences in canopy heights between the beech and Douglas fir sub-plots) and/or to instrumental problems (because a part of these disturbances are removed by the (co)sine correction).

The third effect suggests that the average streamlines are not distributed in a plane around the tower, and it therefore seems logical to include these departures from the sinusoid in the correction. This justifies the use of the NPFM rather than the PFM in this case. 
Besides this, the question of the origin of the offset that appeared in the correction should be addressed. The offset cannot be explained by a thermally driven local circulation because the measurements used to establish the relationship were obtained only under near-neutral conditions. Neither can it be explained by the site topography, since as the site is characterised by a gentle and uniform slope around the tower of $3 \%$. We therefore supposed that the offset is due mainly to the anemometer.

To check this, we applied the (co)sine correction (Eq. 4) with the Van der Molen et al. (2004) coefficients to the raw data. The relationship between the (co)sine-corrected tilt angle and the azimuthal angle is presented for the two sonics in Fig. 8 (triangles), where it is clear that the (co)sine correction significantly reduces the offset in both cases confirming its instrumental origin. However, it does not remove it completely. Indeed, an offset of $0.5^{\circ}$ and $-0.5^{\circ}$ remained for the $\mathrm{R} 2$ and the $\mathrm{R} 3$, respectively. This is probably because the (co)sine calibration is not entirely generic, contrary to the conclusions reached by Van der Molen et al. (2004). Ideally, the offset should be analysed individually and rigorously for each sonic using a proper wind-tunnel calibration. This technical offset is likely to be dependent on wind speed. This has been shown particularly in a recent comparison of this type of sonic anemometer with a hot-film anemometer (Loescher et al. 2005). The technical offset removed by the NPFM established under strong wind conditions is probably greater than the technical offset present in the data under low wind conditions. Under those conditions, because the NPFM was established under strong wind conditions and we applied it to obtain $\bar{w}$ in low wind conditions, it is possible that the final values of $\bar{w}$ are over-corrected.

The evolution with stability of $\bar{w}$ obtained with the Gill R2 is presented in Fig. 9; $\bar{w}$ is practically zero in unstable and near-neutral conditions and negative in the stable range. Similar behaviour has been observed at other sites (Lee 1998; Aubinet et al. 2005).

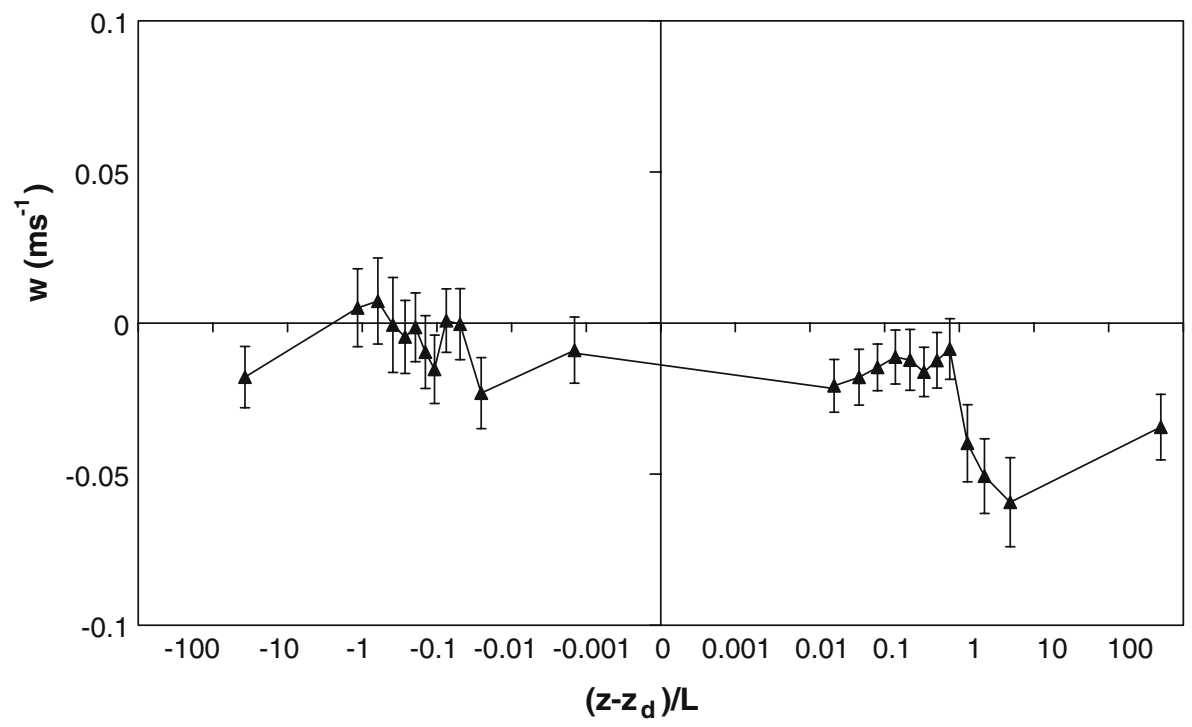

Fig. 9 Bin-average evolution of corrected $\bar{w}$ with atmospheric stability parameter. Obtained from Gill R2. Each point corresponds to 100 data. Error bars are standard error of the mean 
The vertical velocity estimates obtained by applying the first method (NPFM) to the two sonic measurements were compared, with stable conditions only selected because they correspond to periods with important vertical $\mathrm{CO}_{2}$ gradients and therefore possible important vertical advection. The results of the linear regression between both $\bar{w}$ measurements are given in Fig. 10. Although there is a significant correlation between the two measurements, the agreement is not very good, the slope of the regression being only $0.73 \pm 0.02$ and the Rsq 0.56. An estimation of the uncertainty of the measurement is given by the standard deviation of the $\bar{w}$ differences: it is $0.042 \mathrm{~m} \mathrm{~s}^{-1}$. This shows that the uncertainty regarding half-hourly $\bar{w}$ estimates is very large despite the precautions taken throughout the data analysis. The uncertainty could result from the application of the method itself or from the spatial variability of $\bar{w}$.

In addition to the significant uncertainty that affects $\bar{w}$, the representativeness of the measurement is questionable. First, as $\bar{w}$ is measured at the tower top while the drainage sub-layer is confined to the lower part of the canopy, the former could be non-representative of the real flow that is feeding the latter. A solution would be to measure the vertical velocity at a lower height. However, the NPFM is difficult to apply in these conditions, the long-term streamlines describing a complicated pattern due to the presence of obstacles in the canopy. Attempts made at Vielsalm inside the canopy (data not shown) gave mean tilt angles of between zero and $20^{\circ}$, depending on the sector of the incoming wind and affected by great variability within the wind sectors. The resulting correction is one order of magnitude greater than the corrected value and the application of the NPFM is meaningless. Another flaw in these methods is that $\bar{w}$ is estimated at a single point, giving no information about the spatial variability of this variable.

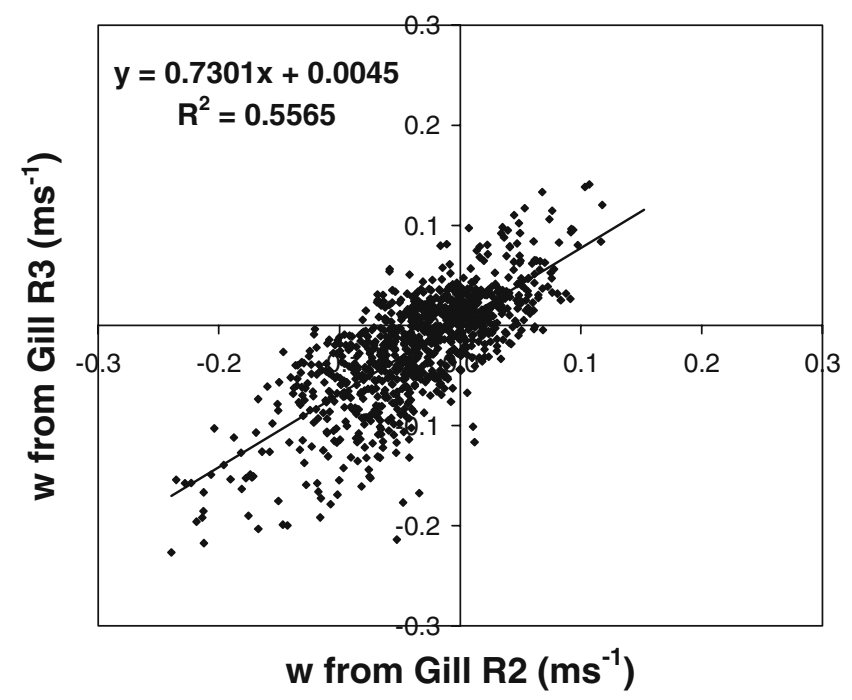

Fig. 10 Comparison between $\bar{w}$ (NPFM corrected) from Gill R2 and Gill R3 separated by a distance of $2 \mathrm{~m}$ at the top of the tower. Established over a period of four months and only for stable conditions $\left(\left(z-z_{d}\right) / L>0.3\right)$ 
All these problems indicate the need for alternative methods to estimate the vertical velocity. The third method is derived from the continuity Eq. (5) and requires two vertical profiles of horizontal velocity. The advantage of this method is that $\bar{w}$ is estimated by an integration along the whole horizontal transect rather than from a single measurement. In addition, it is expected to give a more realistic value of the mass flow increase in the drainage sub-layer than a measurement taken at the canopy top, well above the drainage sub-layer. However, this method is also very imprecise because it is based on the estimation of a difference between horizontal velocities that are small and therefore affected by great uncertainty. In addition, and due to our particular experimental set-up, it can be applied only when the direction of the flow is well known (i.e., in 2D patterns). A previous attempt to estimate $\bar{w}$ from the mass balance was made by Staebler (2003) in the Harvard forest, but was not successful, probably because this site has important understorey vegetation and a more complex local topography, and consequently the drainage sub-layer does not exhibit a clear 2D pattern.

We tested the mass balance method at Vielsalm by using the horizontal velocity measurements made on the upper and lower auxiliary masts, and restricted ourselves to periods when wind directions were between $\pm 5^{\circ}$ of the horizontal transect direction and the $2 \mathrm{D}$ character of the flow was thus proven. The measurements were linearly interpolated horizontally and extrapolated vertically assuming a constant divergence between 0 and $20 \mathrm{~m}$ so as to characterise the mass flow in the whole drainage sub-layer. The coherence of the mass balance measurements in the trunk space was confirmed by the strong positive correlation between the velocity differences observed at 3 and $6 \mathrm{~m}$ (Fig. 11).

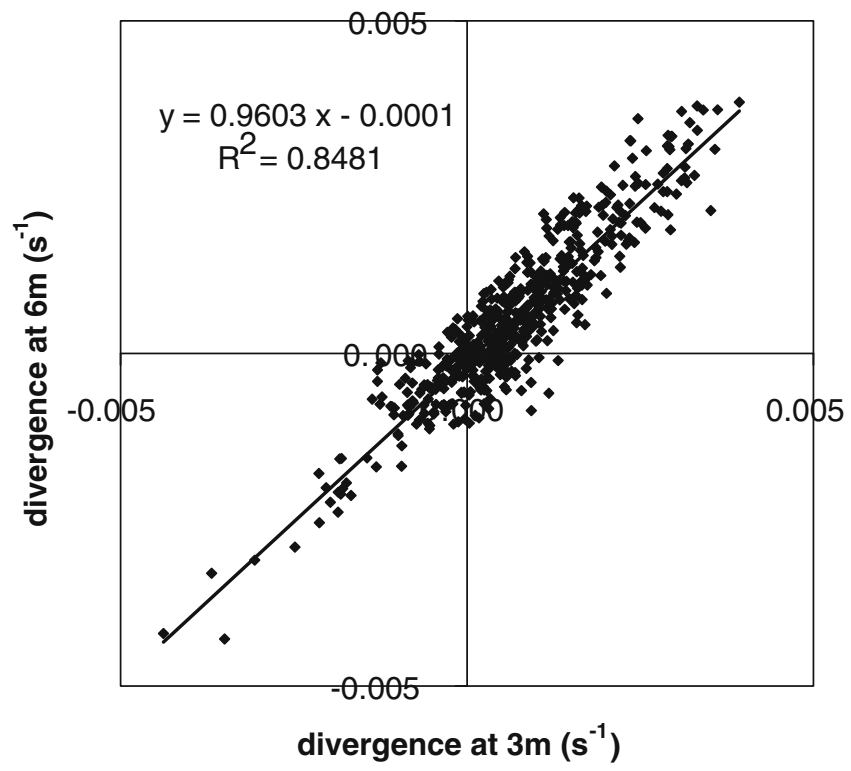

Fig. 11 Comparison between divergences of horizontal wind obtained at two heights within the drainage sub-layer 


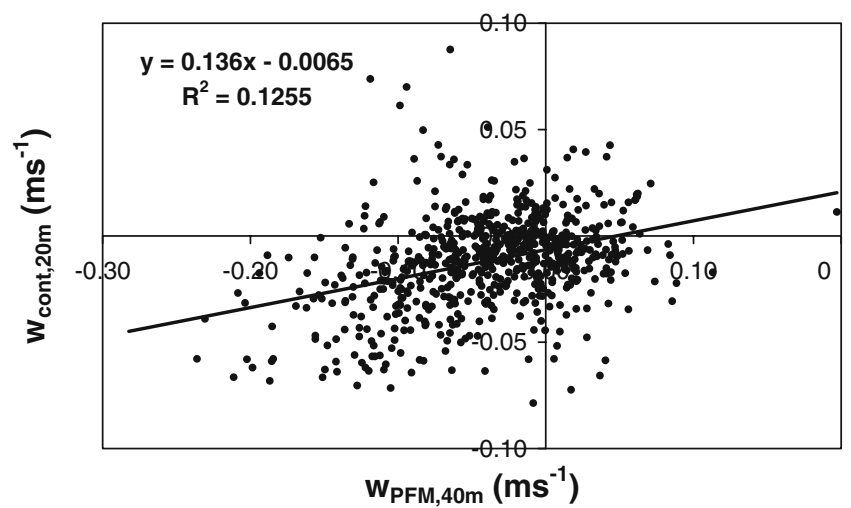

Fig. 12 Comparison between $\bar{w}$ obtained by the divergence of $\bar{u}$ in the trunk space and $\bar{w}$ obtained from NPFM at the top of the tower. Data for stable atmospheric conditions only and for $\bar{u}$ aligned within $5^{\circ}$ of the horizontal transect direction

Figure 12 compares the $\bar{w}$ estimates reached using the two methods. Despite a very large spread, a significant correlation is observed between the single point and the mass balance estimates of the vertical velocity. This confirms that an increase in the horizontal mass flow in the drainage sub-layer is observed under conditions of negative vertical velocity. However, it also appears that the slope of the relationship between the mass balance and single-point estimates is about 0.13 and that its Rsq is small. The large spread of the relationship can be attributed to the significant uncertainty affecting both procedures. We have already discussed the causes of uncertainty in both methods. However, if this uncertainty produces some spread in the relationship, it does probably not explain the systematic difference, the single-point estimate being about one order of magnitude larger than the mass balance estimate. Even if a linear decrease of $\bar{w}$ is postulated together with a drainage sub-layer height of $20 \mathrm{~m}$, the single-point estimate at the top of the drainage sub-layer is still four times greater than the mass balance estimate at the same position.

Systematic errors on the single point estimate could result from the measurement positioning, as suggested earlier. On the other hand, systematic errors could also affect the mass balance estimates: they could be due to the extrapolation method used to estimate the mass flow increase from measurements at only two heights or to the simplification of the pattern to reduce it to two dimensions. In order to determine which method gives the best estimation, it is possible to compute the vertical advection that results from these measurements. By assuming a vertical concentration difference of $-6 \mu \mathrm{mol} \mathrm{mol}^{-1}\left(\bar{c}_{\mathrm{h}}-\langle c\rangle\right)$ in Eq. 2$)$, the resulting vertical advection should reach $9 \mu \mathrm{mol} \mathrm{m}{ }^{-2} \mathrm{~s}^{-1}$ if based on the single-point estimates and $1.2 \mu \mathrm{mol} \mathrm{m}^{-2} \mathrm{~s}^{-1}$ if based on the mass balance approach. The first gives unrealistically large estimates of the vertical advection, and their inclusion in the $\mathrm{CO}_{2}$ budget leads to a great imbalance. On the contrary, the second estimate gives more realistic fluxes and allows a better equilibration of the carbon balance to be made. All these arguments suggest that the mass balance constitutes an interesting alternative to the single-point estimate of $\bar{w}$. It is clear, though, that the method suffers from uncertainty and remains difficult to apply when the velocity pattern cannot be reduced to 2D. Feasibility studies about the use of the mass balance method on other sites should be considered. 


\section{Conclusions}

The uncertainty affecting the evaluation of the horizontal $\left[\mathrm{CO}_{2}\right]$ gradient in the trunk space and the vertical velocity above the canopy were investigated on the forested experimental site of Vielsalm. The analysis enabled us to determine an optimal $\left[\mathrm{CO}_{2}\right]$ measurement strategy. The cycling period should be as short as possible, without running into cross-contamination problems, in order to reduce sampling uncertainty. In our case, a cycling period of 3 min through 20 inlet points allowed the sampling uncertainty on horizontal gradients to be reduced to $1.3 \mu \mathrm{mol} \mathrm{mol}^{-1}$. This important noise highlights the need for long field campaigns to obtain reliable estimates of $\mathrm{CO}_{2}$ gradients.

Under stable conditions, the along-slope $\left[\mathrm{CO}_{2}\right]$ gradient was found to be very uniform for two transect locations across-slope separated by $50 \mathrm{~m}$. This indicated that it is possible to obtain coherent measurements of horizontal $\left[\mathrm{CO}_{2}\right]$ gradient despite the technical difficulties arising from contamination by the vertical gradient. It also showed that at our site the impact of very local sources is limited under stable conditions and that the measurements we obtained are representative at the ecosystem scale. Finally, it showed that the use of a 2D pattern to describe airflow and the $\left[\mathrm{CO}_{2}\right]$ field is justified. In addition, the gradients under stable nighttime conditions were shown to decrease quickly with height, implying that advection affected only the lower third of the drainage sub-layer, which itself extended to only the lower half of the canopy. These gradients are therefore representative of, at least, a control volume delimited by the horizontal transect of $90 \mathrm{~m}$ and the height of the drainage sub-layer $(\approx 20 \mathrm{~m}$, or one half of the canopy height $)$.

Methods used to compute the vertical component of velocity were evaluated, and in our case, the non-planar fit method (NPFM) was found to be more suitable than the PFM, due to the topographic and land cover irregularities. An important offset was found when relating the tilt angle to the azimuthal angle. Its instrumental origins were established, but generic corrections did not eliminate them completely. The conjunction of the existence of a wind-speed dependent technical offset and the application of the NPFM could introduce a systematic bias in the final values of $\bar{w}$.

A comparison of measurements by sonic anemometers placed $2 \mathrm{~m}$ apart above the canopy showed that the uncertainty on corrected $\bar{w}$ was $0.042 \mathrm{~m} \mathrm{~s}^{-1}$, which is of the same order of magnitude as the velocity itself. In addition, as the drainage sub-layer is restricted to the lowest part of the canopy, the representativeness of the vertical velocity is questionable. The estimation of vertical velocity is currently the larger source of error when computing advection terms for the site of Vielsalm. An alternative to computing $\bar{w}$ can be achieved by applying the mass balance equation. The estimation of the divergence of the horizontal wind speed in the trunk space has been shown to give coherent results. The vertical velocity estimated using this technique was found to be fairly well correlated with those deduced from single-point measurements but four times lower. However, this value gives a more realistic advection estimation and seems to improve the $\mathrm{CO}_{2}$ budget closure at the site.

Acknowledgements This research was supported by the European Commission, Programme Environment and Climate, project CARBOEUROFLUX under contract EVK2-CT-1999-00032. In addition, the team was supported by the Fonds National de la Recherche Scientifique (Belgium). We are also grateful for valuable discussions with Christian Feigenwinter. 


\section{References}

Aubinet M, Grelle A, Ibrom A, Rannik Ü., Moncrieff J, Foken T., Kowalski AS, Martin PH, Berbigier P, Bernhofer C, Clement R., Elbers J, Granier A, Grünwald, T., Morgenstern K, Pilegaard K., Rebmann C, Snijders W, Valentini R, Vesala T (2000) Estimates of the annual net carbon and water exchange of forests: the EUROFLUX methodology. Adv Ecol Res 30:113-175

Aubinet M, Chermanne B, Vandenhaute M, Longdoz B, Yernaux M, Laitat E (2001) Long term carbon dioxide exchange above a mixed forest in the Belgian Ardennes. Agric Forest Meteorol 108: 293-315

Aubinet M, Heinesch B, Yernaux M (2003) Horizontal and vertical $\mathrm{CO}_{2}$ advection in a sloping forest. Boundary-Layer Meteorol 108:397-417

Aubinet M, Berbigier P, Bernhofer C, Cescatti A, Feigenwinter C, Granier A, Grunwald T, Havrankova K, Heinesch B, Longdoz B, Marcolla B, Montagnani L, Sedlak P (2005) Comparing $\mathrm{CO}_{2}$ storage and advection conditions at night at different CARBOEUROFLUX sites. BoundaryLayer Meteorol 116:63-94

Baldocchi D, Finnigan J, Wilson K, Paw UKT, Falge E (2000) On measuring net ecosystem carbon exchange over tall vegetation on complex terrain. Boundary-Layer Meteorol 96:257-291

Feigenwinter C, Bernhofer C, Vogt R (2004) The influence of advection on the short term $\mathrm{CO}_{2}$ budget in and above a forest canopy. Boundary-Layer Meteorol 113:201-224

Finnigan JJ (1999) A comment on the paper by Lee (1998): on micrometeorological observations of surface-air exchange over tall vegetation. Agric Forest Meteorol 97:55-64

Finnigan JJ, Clement R, Malhi Y, Leuning R, Cleugh HA (2003) A re-evaluation of long-term lux measurement techniques Part I: Averaging and coordinate rotation. Boundary-Layer Meteorol 107:1-48

Gash JHC, Dolman AJ (2003) Sonic anemometer (co)sine response and flux measurement I. The potential for (co)sine error to affect sonic anemometer-based flux measurements Agric Forest Meteorol 119:195-207

Grelle A, Lindroth A (1994) flow distortion by a solent sonic anemometer: wind tunnel calibration and its assessment flux measurements over forest and field. J Atmos Oceanic Technol 11: 1529-1542

Gu L, Falge E, Boden T, Baldocchi DD, Black TA, Saleska S. R., Suni T, Vesala T, Wofsy S, Xu L (2005) Observing threshold determination for nighttime eddy flux filtering. Agric Forest Meteorol 128:179-197

Heinemann D, Langner D, Stabe U, Waldl HP (1997) Measurement and correction of Ultrasonic Anemometer errors and impact on turbulence measurements. The European Wind Energy Conference, Dublin, pp. 409-412

Högström U, Smedman AS (2004) Accuracy of sonic anemometers: laminar wind-tunnel calibrations compared to atmospheric in situ calibrations against a reference instrument. Boundary-Layer Meteorol 111:33-54

Kaimal JC, Finnigan JJ (1994) Atmospheric boundary-layer flows: their structure and measurements. Oxford University Press, New York, 289 pp

Laitat E, Chermanne B, Portier B (1999) Biomass, carbon and nitrogen allocation in open top chambers under ambient and elevated $\mathrm{CO}_{2}$ and in a mixed forest stand. A tentative approach for scaling up from the experiments of Vielsalm. In: Forest ecosystem modelling, upscaling and remote sensing. Academic Publishing, The Hague, The Netherlands, pp 33-60

Lee X (1998) On micrometeorological observations of surface-air exchange over tall vegetation. Agric Forest Meteorol 91:39-49

Lee X (1999) Reply to the comment by Finnigan on micrometeorological observations of surface-air exchange over tall vegetation. Agric Forest Meteorol 97:65-67

Lee X, Massman W, Law B (2004) Handbook of micrometeorology: a guide for surface flux measurement and analysis. Kluwer Academic Publishers, Dordrecht, The Netherlands, $250 \mathrm{pp}$

Loescher HW, Ocheltree T, Tanner B, Swiatek E, Dano B, Wong J, Zimmerman G, Campbell J, Stock C, Jacobsen L, Shiga Y, Kollas J, Liburdy J, Law BE (2005) Comparison of temperature and wind statistics in contrasting environments among different sonic anemometer-thermometers. Agric Forest Meteorol 133:119-139

Marcolla B, Cescatti A, Montagnani L, Manca G, Kerschbaumer G, Minerbi S (2005) Role of advective fluxes in the carbon balance of an alpine coniferous forest. Agric Forest Meteorol 130:193-206

Massman WJ, Lee X (2002) Eddy covariance flux corrections and uncertainties in long term studies of carbon and energy exchanges. Agric Forest Meteorol 113:121-144

Paw UKT, Baldocchi DD, Meyers TP, Wilson KB (2000) Correction of eddy-covariance measurements incorporating both advective effects and density fluxes. Boundary-Layer Meteorol 97:487-511 
Shimizu T, Suzuki M, Shimizu A (1999) Examination of a correction procedure for the flow attenuation in orthogonal sonic anemometers. Boundary-Layer Meteorol 93:227-236

Staebler RM (2003) Forest subcanopy flows and micro-scale advection of carbon dioxide. Ph. D. dissertation, University of New York, Albany, NY, 179 pp

Staebler RM, Fitzjarrald DR (2004) Observing subcanopy $\mathrm{CO}_{2}$ advection. Agric Forest Meteorol 122:139-156

Taylor JR (1997) An introduction to error analysis. University Science Books, Sausalito, CA, 327 pp

Van der Molen MK, Gash JHC., Elbers JA (2004) Sonic anemometer (co)sine response and flux measurement II. The effect of introducing an angle of attack dependent calibration. Agric Forest Meteorol 122:95-109

Wang S, Yernaux M, Deltour J (1999) A networked two-dimensional sonic anemometer system for the measurement of air velocity in greenhouses. J Agric Eng Res 73:189-197

Wieser A, Fiedler F, Corsmeier U (2001) The influence of the sensor design on wind measurements with sonic anemometer systems. J Atmos Oceanic Technol 18:1585-1608

Wilczack J, Oncley SP, Stage SA (2001) Sonic anemometer tilt correction algorithms. Boundary-Layer Meteorol 99:127-150

Yi CX, Monson RK, Zhai ZQ, Anderson DE, Lamb B, Allwine, G., Turnipseed AA, Burns SP (2005) Modeling and measuring the nocturnal drainage flow in a high-elevation, subalpine forest with complex terrain. J Geophys Res-Atmos 110: 1-13 